\title{
How Does a Portfolio Manager Balance the Relationship Between Money Management and Investment?
}

\author{
Liurui Deng ${ }^{1}$, Lan Yang ${ }^{1} \&$ Bolin $\mathrm{Ma}^{2}$ \\ ${ }^{1}$ Business School, Hunan Normal University, China \\ ${ }^{2}$ College of Mathematics,Physics and Information Engineering, Jiaxing University,China \\ Correspondence: Liurui Deng, Business School, Hunan Normal University, China.
}

Received: May 30, 2019

doi:10.11114/aef.v6i4.4340
Available online: June 24, 2019

URL: https://doi.org/10.11114/aef.v6i4.4340

\begin{abstract}
A portfolio manager can obtain profits from charging management fees to individual investors for helping them to invest. Moreover, as an insider, the portfolio manager can obtain proportional brokerage charges on the return on investment by investing the individual investors' money that he manages. How does the manager balance money management and investment to maximize his total profits? This is the problem that we study in this article. We model the relationship between money management fees and the amount invested. In addition, we investigate how to determine money management fees and the amount of investment needed to maximize the manager's total profits, including from management fees and brokerage charges.
\end{abstract}

Keywords: money manager, institutional investor, individual investor, insider, money management fee

JEL: G20, C02, C52

\section{Introduction}

Portfolio managers always play a vitally important role in financial markets. They can encourage individual investors to invest in risky assets by providing investment assistance. Moreover, as insiders, portfolio managers can affect the liquidity and equilibrium prices of risky assets in the financial market. Therefore, many researchers are interested in portfolio managers.

There is a substantial literature on incentives in principal-agent relationships. Sap-pington discusses the frictions that lie at the heart of incentive problems and proposes the principal's optimal responses to these frictions (see Sappington, 1991). Prendergast illustrates an incentive for workers to conform to the opinions of their supervisors when firms use subjective performance evaluation (see Prendergast, 1993). In a continuous-time principal-agent framework, Hui studies the contracting problem between an individual in-vestor and a professional portfolio manager(see Hui, 2003). In the same framework, Kraft and Korn study the issue of how to delegate an investor's portfolio decision to a portfo-lio manager(see Kraft and Korn, 2008). In a discrete-time principal-agent framework, Liu and Liang study the portfolio selection and contracting problems between an individual investor and a professional portfolio manager (see Liu and Liang, 2009). Sato proposes a model of asset market equilibrium with portfolio delegation and optimal fee contracts(see Sato, 2016). Our novelty is, in the CPT setup, concentrating on trust as distinct from performance in shaping incentives. Many researchers focus on incentives for money man-agers. Chevalier and Ellison, using semiparametric modeling, report that the shape of the flow-performance relationship creates incentives for fund managers to raise or reduce the riskiness of a fund and that these incentives depend on the fund's year-to-date return (see Judith and Ellison, 1997). By examining the labor market for mutual fund managers, they find that "termination" is more performance-sensitive for younger managers (see Judith and Ellison, 1999). They also identify possible implicit incentives created by the termination-performance relationship. The shape of the termination-performance relationship may give younger managers an incentive to avoid unsystematic risk. Inderst and Ottaviani focus on distorted incentives to sell financial products, distortions that arise not only from actual kickbacks but also from the difficulty of incentivizing salesmen to sell the appropriate prod-ucts (see Roman and Ottaviani, 2009, 2012a,b). Guerrieri and Kondor demonstrate that performance generates a "reputational premium" that influences investors' decisions to hire or fire money managers (see Veronica and Kondor, 2012). Hackethal, Inderst, and Meyer find that retail investors who report a heavy reliance on their advisors' recommendations have a substantially higher trading volume and purchase a higher fraction of investment products that their advisors were 
incentivized to sell (promoted products)-see Hackethal et al. (2012). Gennaioli, Shleifer and Vishny focus on the incentives of the money manage-ment organization itself when its clients' choices are mediated by trust (see Gennaioli et al., 2015).

Money managers not only provide investment assistance for individual investors but also invest in risky assets. Because they know some information about risky assets, they are al-ways called "informed traders" or "insiders". Their investment strategies have considerable influence on the liquidity and equilibrium prices of risky assets in financial markets, and therefore, many researchers investigate how managers invest in risky assets.

We cite the essential literature on incentives for an insider's trading strategy. Kyle pro-poses a dynamic trading strategy with informed insiders (see Kyle, 1985). Huddart et al. provide a solution to a discrete-time analog of Kyle's(see Kyle, 1985) rational expectations trading model in which an insider, endowed with long-lived private information, must dis-close the quantity that he trades at the close of each round of trading (see Huddart et al., 2001). Ge and Zheng investigate both the determinants and potential effects of portfolio disclosure frequency by comparing funds providing voluntary quarterly disclosure to funds providing only mandatory semiannual disclosure(see Ge ahnd Zheng, 2015). Agarwal et al. examine the impact of mandatory portfolio disclosure by mutual funds on stock liquidity and fund performance. We develop a model of informed trading with disclosure and test its predictions using the May 2004 SEC regulation requiring more frequent disclosure (see Agarwal et al., 2015).

Previous works consider only one type of profits: management fees or brokerage charges. They do not address the relationship between management fees and brokerage charges. However, in real markets, both management fees and brokerage charges are involved in a manager's total profits and influence one another. Hence, we focus on the relationship between management fees and brokerage charges in maximizing total profits.

To solve this optimization problem, we discuss the relationship between management fees and brokerage charges in greater detail. Assuming that a manager only uses individual investors' money (and not his own) to invest, the management fees affect the amount of investment, the return on investment and the brokerage charge. Specifically, when the manager decreases his management fees, his profits from them might decrease. However, as the management fees decrease, more individual investors might prefer the manager's assistance, and thus, the funds managed by the manager might then increase. Hence, both the returns on investment and brokerage charges increase. Conversely, when the manager increases his management fees, his profits from them might increase. However, as the management fees increase, fewer individual investors might prefer the manager's assistance, and thus, the funds managed by the manager might then decrease. In this case, both the returns on investment and brokerage charges decrease.

This relationship means that a manager has to balance the level of management fees and the amount of funds invested with him to remain viable in a competitive financial market. This issue is the key problem we research in this article. To the best of our knowledge, we are the first to address this problem. As mentioned above, our research is a closer approximation of a real market than are previous works.

However, this original problem presents us with some difficulties. In terms of market characteristics and research perspectives, money management and investing in risky assets are different problems. Hence, previous work uses different research methods to solve the two problems. However, in our research, we need to simultaneously consider money man-agement and investment in risky assets. How do we investigate the two problems within a unified research framework? This is the primary difficulty in our work. Moreover, we should not only model this relationship between management fees and brokerage charges but also formulate the optimization problem for total profits. Furthermore, based on this model, we need to study how to select a suitable amount of investment and a suitable level of management fees to maximize the manager's total profits. In solving these problems, there is no previous experience to follow. We need to explore these original problems in innovative ways. Additionally, a computational difficulty is to obtain an explicit solution of this maximization problem. In contrast to previous work, our model is more complex be-cause it combines money management with risky investment. Thus, it is difficult to obtain the explicit solution by straightforward computation. Here, we employ Matlab to obtain the solution in explicit form.

In this article, we only research the manager's optimal strategies in a single period and not in a multiple periods. Relying on the framework of the single-period strategy, we will research the multi-period problem later.

The remainder of this paper is organized as follows. In Section 2, we discuss the model, including the basic setup and the problem. In section 3, we derive the manager's optimal strategies to maximize total profits. Section 4 contains the numerical analysis. We also compare our results with the results of traditional approaches.

\section{The Model}

\subsection{The Basic Setup}

We assume the existence of an institutional investor, market makers and individual investors in the market. Half of the 
individual investors are noise investors, and the other half are rational investors.

Trading is structured in three steps as follows:

In step one, rational investors need to choose whether to invest on their own or to invest with a manager's assistance. Specifically, individual investors feel overly anxious or nervous when they invest in risky assets without assistance because they have little financial knowledge and related information. Hence, they are willing to hire money managers or advisors to help them invest. Managers may have indispensable knowledge concerning how to diversify investments or even how to earn a premium. Additionally, money managers provide investors with peace of mind. However, individual investors then have to pay management fees, which decrease the return on a risky asset. Thus, they choose among different expected utilities. We assume that a rational investor with an insider's help chooses a portfolio $x_{1}$ to maximize his expected utility:

$$
\bar{U}_{1}\left(x_{1}, f\right)=R+x_{1}(r-f)-\frac{a}{2} x_{1}^{2} \Sigma,
$$

Where $R$ is the risk-free interest rate, $r$ is the excess return on the risky asset predicted by a rational investor, $\Sigma$ is the variance of the risky asset, and $f$ is the fee charged by the institutional investor.

When the rational investor invests on his own, he chooses a portfolio $x_{2}$ to maximize his expected utility:

$$
\bar{U}_{2}\left(x_{2}\right)=R+x_{2} r-\frac{1}{2} x_{2}^{2} \Sigma .
$$

If $\bar{U}_{1}\left(x_{1}^{*}, f\right)>\bar{U}_{2}\left(x_{2}^{*}, f\right)$, the individual investor prefers the manager's help. Otherwise, he is willing to invest on his own. In this step, a manager needs to determine the amount of the management fees that he will charge, which affects on the amount of individual money managed by him.

In step two, the noise investors invest in the risky asset. Their amount of the investment equals $u$, which is normally distributed with mean zero and variance $\sigma^{2}$. The portfolio manager, as an insider, can observe the liquidation value of the risky asset, denoted $v$, which is normally distributed with mean $p_{0}$ and variance $\Sigma$. The random variables $v$ and $u$ are independently distributed. Based on his observation of $v$, the manager invests $x$ in the risky asset. To accommodate mixed strategies, the insider's trading strategy, denoted $X_{2}$, assigns to outcomes probability distributions defined over quantities traded. However, mixed strategies are not optimal in what follows; the more intuitive interpretation of $X_{2}$ as a measurable function such that $x=X_{2}(v)$ is justified.

Here, we note that since individual investors cannot observe liquidation value of the risky asset, they do not know the real excess return on the risky asset, $v p_{0} R$. Thus, in equation (2.1) and equation (2.2), they only use their estimated value $r$. However, individual investors can estimate the variance based on statistics from historical data. We assume that this estimated variance is approximately equal to the real variance $\Sigma$. Hence, the individual investors use $\Sigma$ in equation (2.1) and equation (2.2).

In step three, the market makers determine the price $p$ at which they trade the quantity necessary to clear the market. When doing so, they observe $x+u$ but not $x$ or $u$ (or $v$ ) separately. While their pricing rule, denoted $P$, can be defined to accommodate randomiza-tion, an intuitive interpretation of $P$ as a measurable real function such that $p=P(x+u)$ is also justified.

We assume that the amount of the manager's investment depends on the amount of funds he manages. In other words, the institutional investor only uses the rational investors' funds that he manages to invest and does not use his own funds to invest.

Assume that $\bar{X}_{1}^{*}$ is the amount of funds managed by a portfolio manager who maximizes total management fees and that $\bar{X}_{2}^{*}$ is the optimal investment in the risky asset that max-imizes the brokerage charges. If $\bar{X}_{1}^{*}>\bar{X}_{2}^{*}$, the manager only needs to charge the optimal fees, as in previous work (see Gennaioli et al., 2015). Then, he invests $X_{2}^{*}$ in the risky asset (see Kyle, 1985) and invests $\bar{X}_{1}^{*}-\bar{X}_{2}^{*}$ in the risk-free asset. With this strategy, the manager can obtain the maximal total fees and the maximal brokerage charges. That is, the manager only needs to choose the same optimal management fees and portfolio as in previous work (see Gennaioli et al., 2015; Kyle, 1985) to maximize his total profits. Therefore, this article mainly focuses on the case in which $\bar{X}_{1}^{*} \leq \bar{X}_{2}^{*}$. When $\bar{X}_{1}^{*} \leq \bar{X}_{2}^{*}$, the manager has to invest all of the funds that he manages managed in the risky asset to maximize his total profits. Therefore, we assume that

$$
\left\{\begin{array}{l}
X_{1}=X_{2} \\
X_{2}=\alpha+\beta v \\
p=p_{0}+C+\lambda\left(X_{2}+u\right)
\end{array}\right.
$$


Where $X_{1}$ is the total amount of funds that the institutional investor manages for the rational investors, $X_{2}$ is an amount of the institutional investor's investment, and $p$ is the risky asset's price as determined by the market makers.

\subsection{The Problem}

First, we separately consider the management fees and brokerage charges. Then, we propose the maximization problem for total profits.

The manager's profits from management fees, denoted $\Pi_{1}$, are given by $\Pi_{1}=f X_{1}$. Let the brokerage rate be $q$. Then, the manager's brokerage charges from investment in the risky asset, denoted $\Pi_{2}$, are given by $\Pi_{2}=q(v-p) X_{2}$.

The expected value of his total profits is as follows:

$$
U\left(f, X_{1}, X_{2}\right)=E\left[\Pi_{1}, \Pi_{2} \mid v\right]=E\left[f X_{1}+q(v-p) X_{2} \mid v\right] .
$$

Our objective is how to choose $f, X_{1}$ and $X_{2}$ to maximize the function $U$. That is,

$$
\max _{f, X_{1}, X_{2}} U\left(f, X_{1}, X_{2}\right)=\max _{f, X_{1}, X_{2}} E\left[f X_{1}+q(v-p) X_{2} \mid v\right]
$$

Traditional works only consider one type of profits: management fees (see Gennaioli et al., 2015) or return on investment (see Kyle, 1985). However, our optimal profits include both management fees, $f X_{1}$, and brokerage charges, $q(v p) X_{2}$. Moreover, in contrast to Kyle's work (see Kyle, 1985), we consider the brokerage charges rather than all of the return on the investment. Because we stipulate that the manager only uses individual investors' money (and not his own) to invest, the manager only gains a percentage of the return, $q$, in the form of the brokerage charges.

\section{The Results}

In this section, we obtain the key result, which is the manager's optimal strategy.

Theorem 3.1. The risky asset's price determined by the market makers is

$$
p=p_{0}+C+\lambda\left(X_{2}+u\right),
$$

$$
\text { where } \lambda=\sqrt{\Sigma} / 2 \sigma \text { and } C=\lambda(r \sqrt{1-\theta}-r) /(q \lambda+\Sigma \theta) \text {. }
$$

The money manager's optimal strategy is as follows: the amount invested in the risky asset is

$$
X_{1}^{*}=X_{2}^{*}=\alpha+\beta v
$$

And the management fee is

$$
f^{*}\left(X_{2}^{*}\right)=-\frac{X_{2}^{*} \Sigma \theta}{2 \text { lambertw }\left(X_{2}^{*} \Sigma \theta / 2 r \sqrt{1-\theta}\right)}+r
$$

Where

$$
\begin{gathered}
\alpha=-\frac{r \sqrt{1-\theta}-r+q p_{0}+q C}{2 q \lambda+\Sigma \theta}=-\frac{\left(r \sqrt{1-\theta}-r+q p_{0}+q C\right)}{q \sqrt{\Sigma} / \sigma+\Sigma \theta} \\
\beta=\frac{q}{2 q \lambda+\Sigma \theta}=\frac{q}{q \sqrt{\Sigma} / \sigma+\Sigma \theta}
\end{gathered}
$$

And lambertw( ) is the Lambert $\mathrm{W}$ function.

The proof of this theorem is provided in Appendix 6.1.

Regarding Kyle's work (see Kyle, 1985), our $\lambda$ and $\beta$ are consistent with his results, while our $p$ and differ from his results.

The quantity $1 / \lambda$ measures the "depth" of the market, i.e., the order flow necessary to induce prices to rise or fall by one dollar. In our results, this measure of market liquidity is still proportional to the ratio of the amount of noise trading to the amount of private information that the informed trader is expected to have. This means that the insider's strategy cannot affect market liquidity. Moreover, our result echoes the view of Bagehot (see Bagehot, 1971) and Kyle (see Kyle, 1985) that market makers compensate themselves for bad trades that result from adverse selection by insiders by making the market less liquid. 
$\beta$ reflects the impact of the liquidation value of the risky asset on the amount invested in the risky asset. Our is still equal to $1=2$ which reflects the same impact of $v$ on the investment in the risky asset as in previous works. This impact is proportional to this measure of market liquidity and is not related to the principal-agent market.

In Kyle's research (see Kyle, 1985), $p$ only depends on $p 0$, and $X 2+u$. However, our $p$ depends on $C=r \sqrt{1-\theta}$ in addition to $p_{0}, \lambda$ and $X_{2}+u$. That is, the excess return on the risky asset estimated by individual investors influences the price $p$. In other words, the behavior of the individual investors in the principal-agent market impacts the price determined by the market makers in the capital market. The connection between the two markets is linked to the behavior of the portfolio manager. Specifically, the excess return on the risky asset estimated by individual investors affects the management fees charged by the portfolio manager and the amount of money managed by the portfolio manager. The amount of money managed by the portfolio manager influences the amount of investment in the risky asset, which further affects the price $p$ determined by the market makers in the capital market. Kyle's work shows that is only related to $1 / \lambda$

(the measure of market liquidity) and $p_{0}$. However, our is related to the estimated excess return on the risky asset $r$ and the brokerage rate $q$ in addition to $1 / \lambda$ and $p_{0}$. This is because we consider the optimal amount of investment to maximize total profits, including the brokerage charges and management fees. The brokerage charges are related to the brokerage rate. Moreover, as mentioned above, the management fees and the amount of investment are influenced by the estimated excess return, $r$. Hence, is related to $r$ and $q$. That is, the amount of the investment in the risky asset is related to $r$ and $q$.

\section{Numerical Simulation}

In this section, by numerical simulation, we test the sensitivity to riskiness of the risky asset. Let the risk, $\Sigma$, increase from 1:0 to 5:0. We compare our results with the classical results on the sensitivity of the amount invested (see Figure 1), the sensitivity of the price (see Figure 2), the sensitivity of the management fees (see Figure 3 ) and the sensitivity of total profits (see Figure 4). We set $=0: 5, q=0: 03,=1$ and $p_{0}=10$.

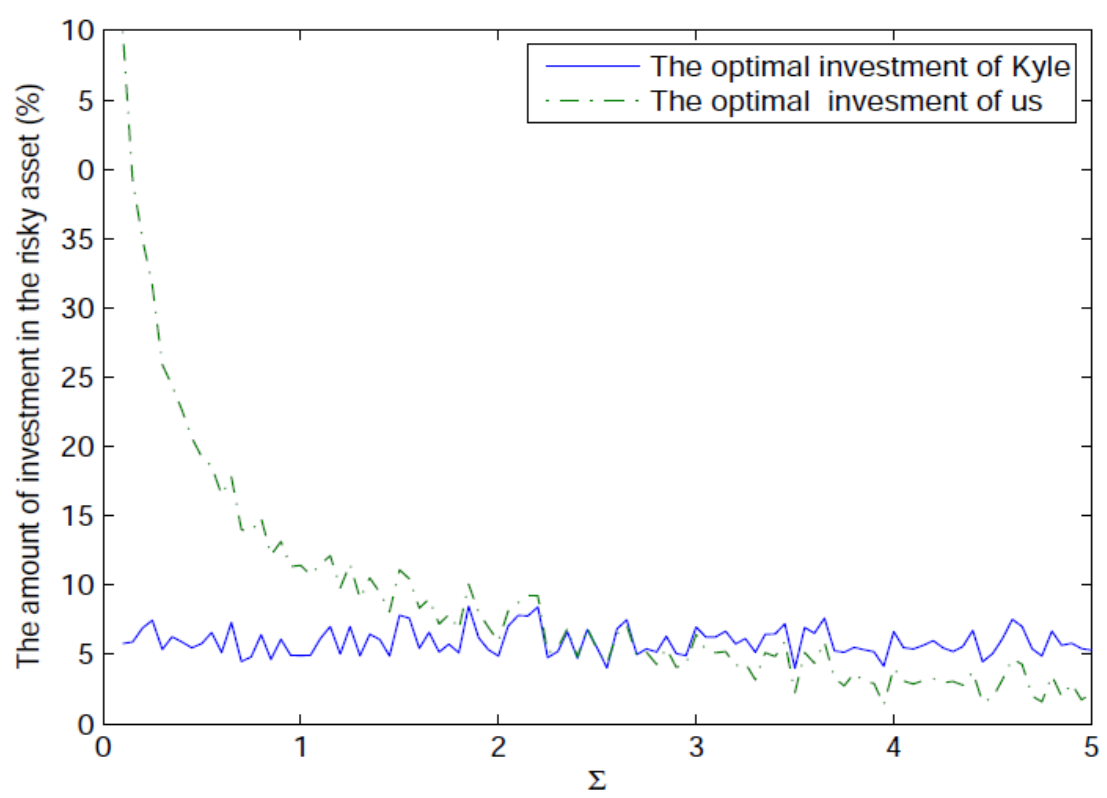

Figure 1 . The sensitivity of the optimal investment to the risks

Figure 1 shows that our optimal strategies are more sensitive to the risks of the risky asset than those of Kyle (see Kyle, 1985). When the variance of the risky asset, $\Sigma$, increases from 0.1 to 5.0, the manager's investment in the risky asset decreases from $30 \%$ to $2 \%$ in our model, while the manager's investment in the risky asset remains at approximately $5 \%$ in Kyle's model. When $\Sigma$ is less than 2:0, the investment in our model is more than that in Kyle's model; when $\Sigma$ increases from 2:0 to 3:0, the investment in our model is almost as much as the investment in Kyle's model; when $\Sigma$ is more than 3:0, the investment in our model is less than the investment in Kyle's model. In our model, the sensitivity of individual investors to risk affects the management fees and the amount of money managed by the manager in Step 1. This amount of the money further affects the amount invested in the risky asset in Step 2. Thus, the sensitivity of individual investors to risk affects the optimal strategies for total profits. However, in Kyle's model, the optimal investment is only affected by the sensitivity of the manager who is the insider in Step 2. Because individual investors are more sensitive to risks than are insiders, our strategies are more sensitive than Kyle's strategies. 


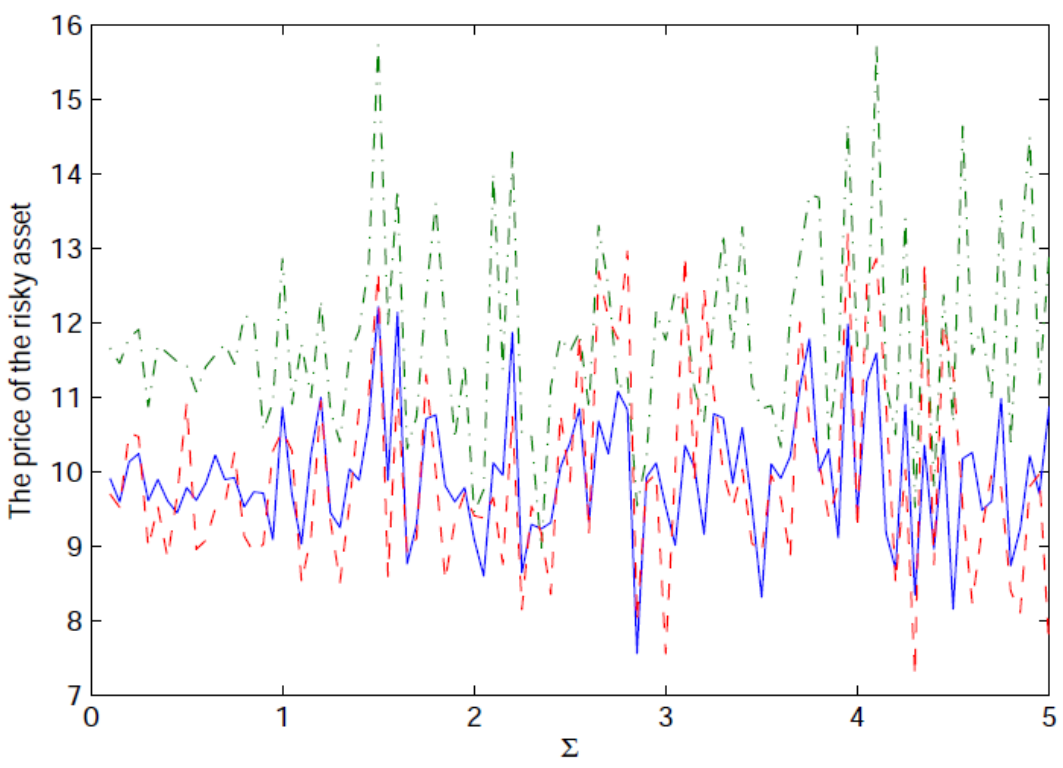

Figure 2. The sensitivity of prices to risk

Figure 2 displays that the price in Kyle's model (see Kyle, 1985) is closer to the real liquidation value of the risky asset than is the price in our model. This reason is that, in Kyle's model, when the market makers determine the price, they only consider the impact of the total amount of the insider's investment and the noise investors' investment. However, in our model, the market makers consider not only the impact of the total amount invested but also the impact of the rational individual investors in Step 1. Specifically, the excess return of the risky asset estimated by the individual investors influences the price. This numerical result is consistent with the theoretical result in Theorem 3.1.

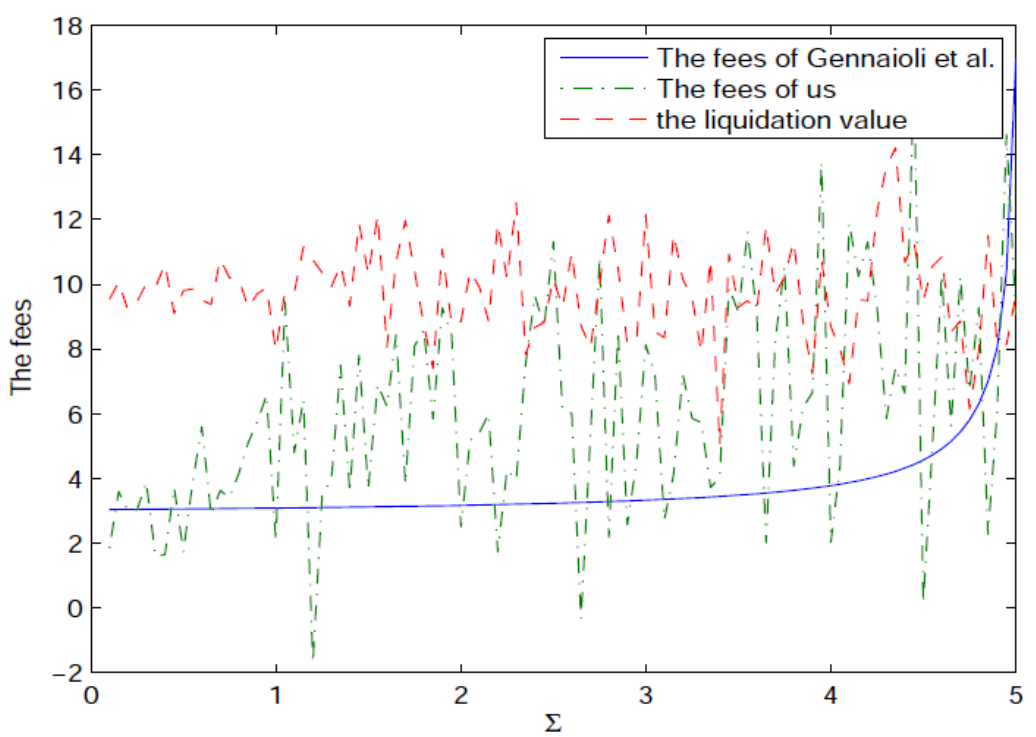

Figure 3. The sensitivity of management fees to risk

From Figure 3, we find that, in Gennaioli et al.'s model (see Gennaioli et al., 2015), the fees increase as the variance increases from 0.1 to 5.0. This reason is that the individual investors prefer to share more risks with the manager as risk increases. Thus, they are willing to pay higher fees to the manager. These fees are not related to the liquidation value of the risky asset in Step 2. However, because we consider total profits, which are affected by the liquidation value of the risky asset, the fees are also influenced by the liquidation value of the risky asset. Hence, our fees oscillate according to the liquidation value of the risky asset. 


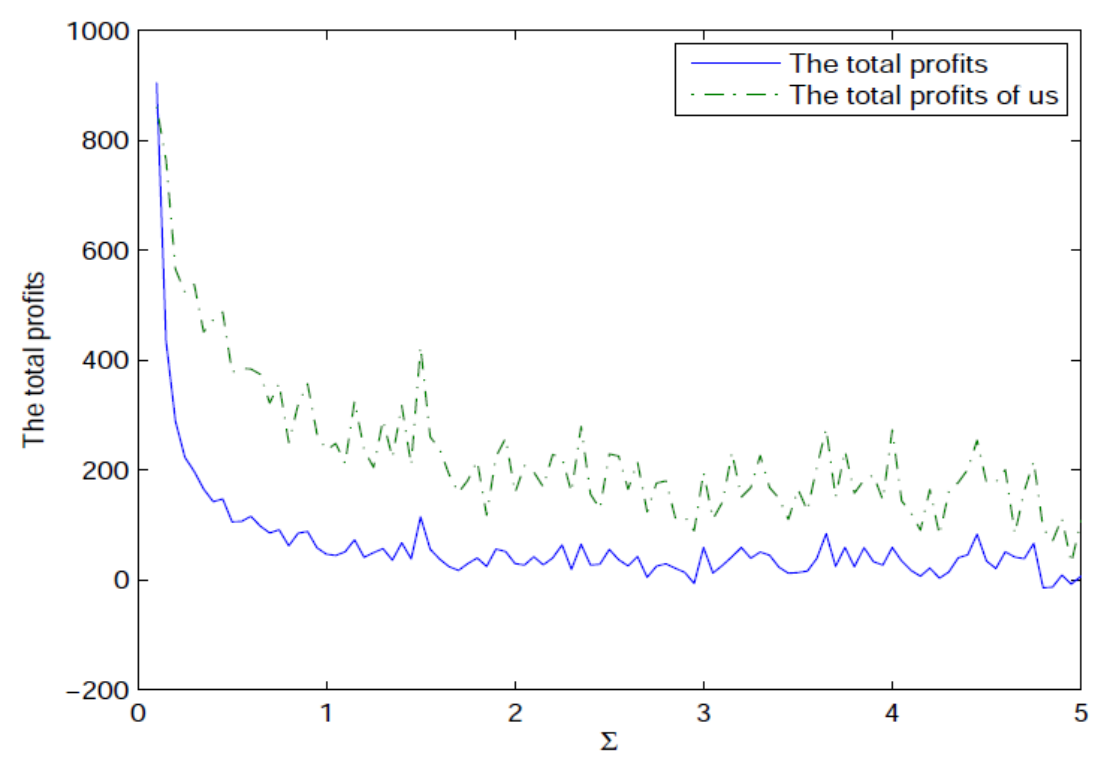

Figure 4. The sensitivity of total pro ts to risk

Figure 4 shows that if the manager chooses our optimal strategies, he will gain more total profits than by using the traditional strategies. This result demonstrates that jointly considering the management fees and the investment is preferable to considering the man-agement fees or the investment in isolation. If we only consider the management fees, when the optimal strategy maximizes the management fees, this strategy might make the return on the investment small, which would lead to low total profits. Hence, in this case, this strategy is not the optimal strategy with respect to total profits. Considering only the return on the investment in the risky asset produces a case similar to the above.

\section{Appendix}

The proof of Theorem 3.1

Let the insider's profits from the rational investors be $\Pi_{1}$ and his return through investment in the risky asset be $\Pi_{2}$. Then, the expected value of his total profit is as follows:

$$
U=E\left[\Pi_{1}, \Pi_{2} \mid v\right]=E\left[f X_{1}+q(v-p) X_{2} \mid v\right] .
$$

Noting that $p=p_{0}+C+\lambda\left(X_{2}+u\right)$ and $\mathbf{X}_{1}=\mathbf{X}_{2}$, we have

$$
U=E\left[f\left(X_{2}\right) X_{2}+q\left(v-p_{0}-C-\lambda\left(X_{2}+u\right)\right) X_{2}\right] .
$$

To maximize his total profits, we obtain the derivative of this expected value with respect to $X_{2}$ and set it equal to zero: Since $E[u]=0$, we have

$$
f^{\prime}\left(X_{2}\right) X_{2}+f\left(X_{2}\right)+q\left(v-p_{0}-C\right)-2 \lambda q X_{2}=0 .
$$

Now, we consider how to obtain the expressions for $f\left(X_{2}\right)$ and $f^{\prime}\left(X_{2}\right)$. To maximize a rational investor's expected utility, we take the derivative of his expected utility $\bar{U}(x, f)$ with respect to $x$ and set it equal to zero:

$$
\frac{\partial \bar{U}_{1}}{\partial x_{1}}=r-f-a \Sigma x_{1}=0 .
$$

Thus, $x_{1}^{*}=(r-f) / a \Sigma$. When the rational investor has the assistance of a trusted and experienced instituational investor, his optimal portfolio is $x_{2}^{*}=r / \Sigma$.

The investor needs the insider's assistance provided that $\bar{U}_{1}\left(x_{1}^{*}, f\right) \geq \bar{U}_{2}\left(x_{2}^{*}\right)$ which is equivalent to

$$
a \leq \frac{(r-f)^{2}}{r^{2}} .
$$

Hence, the amount of funds managed by an insider charging $f$ is given by 


$$
\begin{aligned}
X_{1} & =\int x_{1}^{*} d a \\
& =\frac{r-f}{\Sigma} \int_{1-\theta}^{\max \left[1-\theta,(r-f)^{2} / r^{2}\right]} \frac{1}{a \theta} d a \\
& =\frac{r-f}{\Sigma \theta}(2 \ln (r-f)-2 \ln r-\ln (1-\theta)) \\
& =X_{2}
\end{aligned}
$$

Using Matlab, we obtain

$$
f\left(X_{2}\right)=-\frac{X_{2} \Sigma \theta}{2 l a m b e r t w\left(X_{2} \Sigma \theta / 2 r \sqrt{1-\theta}\right)}+r
$$

where lambertw( ) is the Lambert $\mathrm{W}$ function.

Based on the Taylor series expansion of the Lambert $\mathrm{W}$ function, we obtain that

$$
f\left(X_{2}\right) \approx-\frac{r \sqrt{1-\theta}}{1-X_{2} \Sigma \theta / 2 r \sqrt{1-\theta}}+r .
$$

Hence, we have

$$
f^{\prime}\left(X_{2}\right) \approx-\frac{2 r^{2}(1-\theta) / \Sigma \theta}{\left(X_{2}-2 r \sqrt{1-\theta} / \Sigma \theta\right)^{2}} .
$$

Applying the Taylor series expansion of $f\left(X_{2}\right) X_{2}+f\left(X_{2}\right)$ at $X_{2}=0$ to (4.3), we obtain

We rearrange terms to obtain

$$
-r \sqrt{1-\theta}+r-\Sigma \theta X_{2}+q\left(v-p_{0}-C\right)-2 q \lambda X_{2}=0 .
$$

$$
X_{2}=-\frac{r \sqrt{1-\theta}-r+q p_{0}+q C}{2 q \lambda+\Sigma \theta}+\frac{q}{2 q \lambda+\Sigma \theta} v .
$$

Now, it is easy to see that

$$
\alpha=-\frac{r \sqrt{1-\theta}-r+q p_{0}+q C}{2 q \lambda+\Sigma \theta}, \quad \beta=\frac{q}{2 q \lambda+\Sigma \theta} .
$$

Since $v$ and $X_{2}$ are normally distributed, from the Projection Theorem, we have

$$
\begin{aligned}
p & =E\left[v \mid X_{2}+u\right] \\
& =E[v]+\frac{\operatorname{Cov}\left[v, X_{2}+u\right]}{\operatorname{Var}\left[X_{2}+u\right]}\left(X_{2}+u-E\left[X_{2}+u\right]\right) .
\end{aligned}
$$

Note that is the slope of a line plotting a random dependent variable $X_{2}$ or $X_{2}+u$ with respect to an independent random va $\dot{\beta}$ able $v$. That is, $\beta=\operatorname{Cov}\left[v, X_{2}+u\right] / \operatorname{Var}\left[X_{2}+u\right]$. Thus,

$$
p=E[v]+\frac{\beta \Sigma}{\beta^{2} \Sigma+\sigma^{2}}\left(X_{2}+u-\alpha-\beta E[v]\right) .
$$

Set $\lambda=\frac{\beta \Sigma}{\beta^{2} \Sigma+\sigma^{2}}$. Combining (4.13) with $p=p_{0}+C+\lambda\left(X_{2}+u\right)$, we obtain

$$
\begin{aligned}
p_{0}+C & =E[v]-\lambda(\alpha+\beta E[v]) \\
& =E[v]+\lambda \frac{r \sqrt{1-\theta}-r+q p_{0}+q C}{2 q \lambda+\Sigma \theta}-\lambda \frac{q}{2 q \lambda+\Sigma \theta} E[v] \\
& =\left(1-\frac{\lambda q}{2 q \lambda+\Sigma \theta}\right) E[v]+\frac{\lambda q}{2 q \lambda+\Sigma \theta} p_{0}+\lambda \frac{r \sqrt{1-\theta}-r+q C}{2 q \lambda+\Sigma \theta} .
\end{aligned}
$$


Let $C=\lambda(r \sqrt{1-\theta}-r) /(q \lambda+\Sigma \theta)$. We can demonstrate that $p_{0}=E[v]$.

From $\lambda=\frac{\beta \Sigma}{\beta^{2} \Sigma+\sigma^{2}}$, we have

$$
\lambda\left(\beta^{2} \Sigma+\sigma^{2}\right)=\beta \Sigma .
$$

We rearrange terms to obtain

Thus, $\lambda=\sqrt{\Sigma} / 2 \sigma$. Therefore,

$$
4 \lambda^{2} \sigma^{2}=\Sigma
$$

$$
\alpha=-\frac{r \sqrt{1-\theta}-r+q p_{0}+q C}{2 q \lambda+\Sigma \theta}=-\frac{\left(r \sqrt{1-\theta}-r+q p_{0}+q C\right)}{q \sqrt{\Sigma} / \sigma+\Sigma \theta}
$$

and

$$
\beta=\frac{q}{2 q \lambda+\Sigma \theta}=\frac{q}{q \sqrt{\Sigma} / \sigma+\Sigma \theta} .
$$

\section{Acknowledgements}

The article is supported by Humanities and social science project of Ministry of Education (No.17YJC790020).

\section{References}

Agarwal, V., Mullally, K. A., Tang, Y., \& Yang, B. (2015). Mandatory portfolio disclosure, stock liquidity, and mutual fund performance. Journal of Finance, 70(6), 2733-2776. https://doi.org/10.1111/jofi.12245

Ge, W. 1., Zheng, L. (2006). The frequency of mutual fund portfolio disclosure, Working paper. https://doi.org/10.2139/ssrn.557186

Gennaioli, N., Shleifer, A., Vishny, R. (2015). Money doctors. J Financ, 70(1), 91-114. https://doi.org/10.1111/jofi.12188

Huddart, S., Hughes, J. S., Levine, C. B. (2001). Public disclosure and dissimulation of insider trades. Econometrica, 69 (3), 665-681. https://doi.org/10.1111/1468-0262.00209

Hui, O. Y. (2003). Optimal contracts in a continuous-time principal-agent problem. Rev of Financ Studies, 16(1), 173-208. https://doi.org/10.1093/rfs/16.1.0173

Judith, C., Ellison, G. (1997). Risk taking by mutual funds as a response to incentives. J Polit Econ, 105, 1167-1200. https://doi.org/10.1086/516389

Judith, C., Ellison, G. (1999). Career concerns of mutual fund managers. Q J Econ, 114, 389-432. https://doi.org/10.1162/003355399556034

Klye, A. S. (1985). Continuous auctions and insider trading. Econometrica, 53(6), 1315-1335. https://doi.org/10.2307/1913210

Kraft, H., Korn, R. (2008). Continuous-time delegated portfolio management with homoge-neous expectations: Can an agency conflict be avoided? Financ Markets and Portfolio Manage, 22(1), 67-90. https://doi.org/10.1007/s11408-007-0067-1

Liu, W., Liu, C., Ge, M. (2009). Asset allocation and optimal contract for delegated portfolio management. Cutting-Edge Research Topics on Multiple Criteria Decision Making 20th International Conference. 713-720. https://doi.org/10.1007/978-3-642-02298-2_106

Prendergast, C. (1993). A theory of "yes men". Am Econ Rev, 83(4), 757-770.

Roman, I., Ottaviani, M. (2009). Misselling through agents. Am Econ Rev, 99, 883-908. https://doi.org/10.1257/aer.99.3.883

Roman, I., Ottaviani, M. (2012a). Competition through commissions and kickbacks. Am Econ Rev, 102, 780-809. https://doi.org/10.1257/aer.102.2.780

Roman, I., Ottaviani, M. (2012b). Financial advice. J Econ Lit, 50, 494-512. https://doi.org/10.1257/jel.50.2.494

Sappington, D. E. M. (1991). Incentives in principal-agent relationships. J Econ Perspectives, 5(2), 45-66. https://doi.org/10.1257/jep.5.2.45 
Sato, Y. (2016). Delegated portfolio management, optimal fee contracts, and asset prices. J Econ Theory, 165, 360-389. https://doi.org/10.1016/j.jet.2016.05.002

Veronica, G., Kondor, P. (2012) Fund managers, career concerns and asset price volatility. Am Econ Rev, 102, 1986-2017. https://doi.org/10.1257/aer.102.5.1986

\section{Copyrights}

Copyright for this article is retained by the author(s), with first publication rights granted to the journal.

This is an open-access article distributed under the terms and conditions of the Creative Commons Attribution license which permits unrestricted use, distribution, and reproduction in any medium, provided the original work is properly cited. 